\title{
Effect of pigment composition on absorption properties of phytoplankton
}

\author{
Nicolas Hoepfiner*, Shubha Sathyendranath \\ Oceanography Department, Dalhousie University, Halifax, Nova Scotia, Canada B3H 4J1 \\ and
}

Bedford Institute of Oceanography, Biological Oceanography Division, Dartmouth, Nova Scotia, Canada B2Y 4A2

\begin{abstract}
Absorption spectra of several phytoplankton species were decomposed, after correction for the particle effect, to estimate in vivo absorption properties of the major light-harvesting pigments in algae. A Gaussian shape is suitable, theoretically and empirically, to represent the absorption spectra of individual photosynthetic components. The Gaussian parameters agreed well with the expected pigment compositions of 3 groups of algae, and the peak heights were linearly correlated with the concentrations of any one of the 4 major pigments measured in the samples. The linear relationship did not vary with phytoplankton species. We present here the first estimates of the 'true' in vivo specific absorption coefficients of 4 major pigments, after correction for particle effect. The results are used to reconstruct the in vivo absorption spectrum of a multi-species sample.
\end{abstract}

\section{INTRODUCTION}

Absorption and scattering by phytoplankton are generally considered to be responsible for most of the variations in the optical properties of open-ocean waters. Knowledge of these inherent optical properties of phytoplankton is therefore a necessary requirement for models of light penetration (Sathyendranath \& Platt 1988), of light utilisation by phytoplankton (Dubinsky et al. 1986, Sakshaug et al. 1989, Smith et al. 1989), and even of mixed-layer dynamics (Lewis et al. 1983, Platt et al. 1984, Kamykowski 1987, Sathyendranath et al. 1991). Bio-optical models for remote sensing of phytoplankton biomass and primary productivity of the oceans are also based on the optical properties of phytoplankton (Gordon \& Morel 1983, Sathyendranath \& Morel 1983, Platt 1986, Platt et al. 1988, Sathyendranath \& Platt 1989). The biomass models are more sensitive to changes in the characteristics of spectral absorption by phytoplankton than to changes in their scattering characteristics (Gordon \& Morel 1983). Absorption by phytoplankton has therefore been the subject of many studies, and some of these studies have paid particular attention to separation of absorption by

- Present address: Institute for Remote Sensing Applications, Advanced Technologies Division, Joint Research Centre, Ispra Establishment, I-21020 Ispra (Varese), Italy living phytoplankton from that by associated detritus and dissolved organic matter (Prieur \& Sathyendranath 1981, Kishino et al. 1984, Iturriaga \& Siegel 1989). Note that this distinction is particularly important in studies of the quantum yield of photosynthesis.

To identify the absorption coefficient of phytoplankton at any wavelength $\lambda$, it is common practice to express the total absorption coefficient $a_{p}(\lambda)$ in terms of a 'specific absorption coefficient', $a^{*}(\lambda)$, and $C$, the concentration of chlorophyll a (chl a), which is the main pigment in phytoplankton:

$$
a_{p}(\lambda)=C a^{*}(\lambda)
$$

Note that phytoplankton absorption is due to absorption not just by the chl a but also by all the auxiliary pigments present. Therefore, $a^{*}(\lambda)$ is not a true specific absorption by chl $a$, but only an apparent one. The composition of the auxiliary pigments and the relative importance of their absorption are variable. This variability in pigment composition has been shown to be 1 of the 2 important factors responsible for the observed variability in the magnitude and spectral form of $a^{*}(\lambda)$ (Sathyendranath et al. 1987), the other factor being the particle effect (also known as the 'flattening effect' or 'package effect'; see Duysens 1956, Kirk 1975, Morel \& Bricaud 1981). Indeed, the magnitude of $a^{\circ}$ at $440 \mathrm{~nm}$ has been shown to vary over a factor of 3 (Sathyendranath 1986). The choice of chl a alone for normaliza- 
tion is dictated primarily on practical grounds - chl $a$ is the pigment that is easiest to measure, and it is routinely measured on most biological oceanographic cruises. Its choice is also justifiable in primary production studies because of the central role it plays in photosynthesis. With recent technical developments, however, measurement of auxiliary pigments is becoming more common, and therefore it would be useful to develop techniques that would account, in a systematic manner, for the consequences of changes in pigment composition on phytoplankton absorption. To do this, we must rewrite Eq. (1) as:

$$
a_{p}(\lambda)=\sum_{i=1}^{n} C_{1} a_{i}^{\prime}(\lambda)
$$

where $C_{1}$ is the concentration of the ith pigment, $a_{i}^{\prime}(\lambda)$ is the 'true' specific absorption coefficient of the ith pigment, and $n$ is the total number of pigments considered (note that chl $a$ is one of the $n$ pigments). To make use of Eq. (2), we need not just the concentrations of the $n$ pigments, but also their specific absorption coefficients.

Very little is known about the in vivo, spectral, specific absorption coefficients of the major phytoplankton pigments. Bidigare et al. (1987) tried to account for the influence of auxiliary pigments, but in the absence of information on the in vivo specific absorption coefficients of the pigments, they were obliged to use the values for extracted pigments from a single culture (Mann \& Myers 1968). However, absorption by phytoplankton pigments is known to change with extraction; besides, estimates from a single culture can hardly be considered statistically valid for application to natural populations. Sathyendranath et al. (1987) tried to estimate the specific absorption coefficients of major phytoplankton pigments, after correction for the particle effect. But the multiple regression method they used did not yield acceptable values of the specific absorption coefficients because of non-zero covariance among the pigments in the sample set used.

In this paper we outline a method for the estimation of in vivo specific absorption coefficients of major phytoplankton pigments. We reanalyze the data of Sathyendranath et al. (1987) but, instead of using multiple regression, we have decomposed the spectra into Gaussian absorption bands. This method is statistically more valid, and is backed by theory as well. The results are based on in vivo spectra that have been corrected for the particle effect, and therefore the specific absorption spectra proposed are not influenced by cell size or intracellular concentration of the pigments. Also, the method is designed for separating absorption by active pigments from any background absorption that may be present. We used in vivo absorption spectra of 20 monospecific cultures that were selected to cover 3 major phytoplankton groups, and therefore we are able to discuss variations in the absorption characteristics between groups. Also, the method does separate successfully the absorptions due to the different pigments, and we show that the specific absorption bands proposed can be used to reconstruct the total absorption coefficient, provided the pigment concentrations are known.

\section{MATERIALS AND METHODS}

Bio-optical data. In vivo absorption spectra, pigment concentrations (chl $a, b, c$ and carotenoids), particle size distribution and cell numbers of 20 different cultures were taken from Sathyendranath et al. (1987). Species in culture included 3 diatoms (Chaetoceros protuberans, Chaetoceros didymum, Skeletonema costatum), 4 Chlorophyceae (Dunaliella marina, Platymonas suecica, Platymonas sp., Tetraselmis maculata) and 2 Prymnesiophyceae (Hymenomonas elongata, Emiliana huxleyi), representing major pigment compositions commonly observed in the marine environment (Gieskes \& Kraay 1986).

The spectrophotometer was designed with a scattered transmission accessory. It consisted of the sample and reference cells placed very close to the detector, with diffusing plates in front of them, to ensure capture of most of the forward scattered light. The absorption spectra were measured from 340 to $760 \mathrm{~nm}$. The cell size for each culture was estimated from cell volume measurements, and expressed as the diameter of an equivalent sphere. Number of cells per unit volume was estimated with hemacytometers. To remove the effects of changes in cell size and intracellular pigment concentrations on absorption, all spectra were corrected for the particle effect (Duysens 1956). This effect is known to flatten the shape of absorption spectra of pigments embedded in particles, compared to that of homogeneous solution of the same pigments. Morel \& Bricaud (1981) and Sathyendranath et al. (1987) have shown that this effect can lead to significant modifications in the absorption spectra of phytoplankton. We used the same algorithms as in Sathyendranath et al. (1987), which assume spherical particles and uniform distribution of the absorbing material within the cells Each absorption spectrum was then corrected for the value at $737 \mathrm{~nm}$, as in Sathyendranath et al. (1987).

Pigment concentrations were measured spectrophotometrically after extraction in $90 \%$ acetone. Chl a was estimated using the equations of Lorenzen (1967); SCOR/UNESCO (1966) equations were used to calculate chl $b$ and $c$, and the method of Richards \& Thompson (1952) was used for carotenoids. 
Decomposition of absorption spectra. The absorption spectrum from 400 to $750 \mathrm{~nm}$ of photosynthetic organisms is characterized by a continuous envelope, reflecting a strong coupling in the transfer of energy between the pigment molecules (Förster 1965). The continuous nature of the spectrum renders it difficult to estimate the contribution to the total absorption by each pigment species, unless the spectrum can be suitably decomposed.

One of the simplest theoretical models of absorption is that of Lorentz, which predicts the shape of absorption bands based on the assumption that electrons and ions can be treated as simple harmonic oscillators in an electromagnetic field (Bohren \& Huffman 1983). This model has been successfully applied to decompose the spectrum of the imaginary part of the refractive index of the alga Platymonas suecica (Bricaud \& Morel 1986). The Lorentz model, however, does not fully account for the effects of overlapping absorption bands and of strong, vibrational interaction between molecules (Knox 1963), as is found in photosynthetic pigments. Toyozawa (1958) proposed a general formalism, which considers the strength of the electron-lattice coupling, for computation of the absorption coefficient. He concluded that, in the presence of a strong interaction between oscillators, an absorption band assumes a Gaussian shape, whereas if the transfer coupling is weak, the absorption tends toward a Lorentzian shape.

Empirical evidence on the decomposition of absorption spectra of chl $a$ in solution (Cotton et al. 1974, Shipman et al. 1976, Katz et al, 1977), and of chlorophyll-protein complexes (French et al. 1972, Larkum \& Barrett 1983), also favours use of Gaussian curves for approximating the individual absorption bands of pigments.

Based on these considerations, absorption spectra in the present study were decomposed using Gaussian curves. A curve-fitting program, initially described by French et al. (1967), was slightly modified and adapted to the needs of this study. The input specifications for each absorption spectrum were as follows: (1) only Gaussian curves were used for the curve-fitting analysis; (2) no weighting of the data was done, i.e. all parts of the spectrum were treated as equally important; (3) the program was set up to run a maximum of 20 iterations per spectrum; (4) the wavelength positions (band center) and the half bandwidths were not allowed to change by more than $1 \mathrm{~nm}$ per iteration.

Since the spectra were corrected for particle effect, the spectral features were emphasized, facilitating initial estimation of the band parameters according to the presence of peaks and shoulders on the observed spectrum. In the initial runs, 8 absorption bands were specified, but it was observed that a better fit was achieved by adding 3 more bands: one at each extremity of the spectrum, and another at around $550 \mathrm{~nm}$. Therefore, a total of 11 Gaussian curves was used to represent the absorption spectra. Further increases in the number of bands did not improve the fitting procedure significantly for most of the cultures. Table 1 summarizes the input parameters of the Gaussian curves. Wavelength positions and halfwidths (in $\mathrm{nm}$ ) of the initial guesses were kept the same for all analyses, whereas the initial height of each band (in $\mathrm{m}^{-1}$ ) was changed according to the biomass in each culture.

\section{RESULTS}

Fig. 1 shows the observed and estimated absorption spectra for 3 phytoplankton species from distinct taxonomic groups, together with the results of the decomposition program. In all cases, 20 iterations were sufficient to allow the convergence criterion (percentage difference in standard deviation between successive iterations of the curve fitting) to be $<0.1 \%$. Maximum deviation of the fitted curve from the observed spectrum was $<1 \%$ of the band heights. Maxima of errors were in the 450 to $600 \mathrm{~nm}$ region of the spectrum and around $650 \mathrm{~nm}$, which corresponds to absorption by accessory pigments.

Table 2 indicates the average positions and the halfwidths of the 11 Gaussian curves estimated for the 3 algal groups. The peak positions changed little compared to the initial inputs. The halfwidths, however, changed by as much as $19 \mathrm{~nm}$ during the computation. Analyses of variances were applied to each of the bands to detect any trends in the variations of the Gaussian parameters (Table 3). In almost all cases, the parameters of different algal groups differed more from each other than did the individual values within any one group. In other words, the null hypothesis that the

Table 1. Input specifications of the Gaussian parameters for decomposition of absorption spectra of 4 phytoplankton species

\begin{tabular}{|c|c|c|c|c|c|c|c|c|c|c|c|}
\hline \multirow[t]{2}{*}{ Gaussian parameters } & \multicolumn{11}{|c|}{ Gaussian band number } \\
\hline & 1 & 2 & 3 & 4 & 5 & 6 & 7 & 8 & 9 & 10 & 11 \\
\hline Wavelength position (nm) & 380 & 415 & 440 & 460 & 500 & 545 & 580 & 620 & 645 & 675 & 700 \\
\hline Halfwidth (nm) & 50 & 20 & 40 & 35 & 50 & 30 & 30 & 30 & 30 & 35 & 40 \\
\hline
\end{tabular}



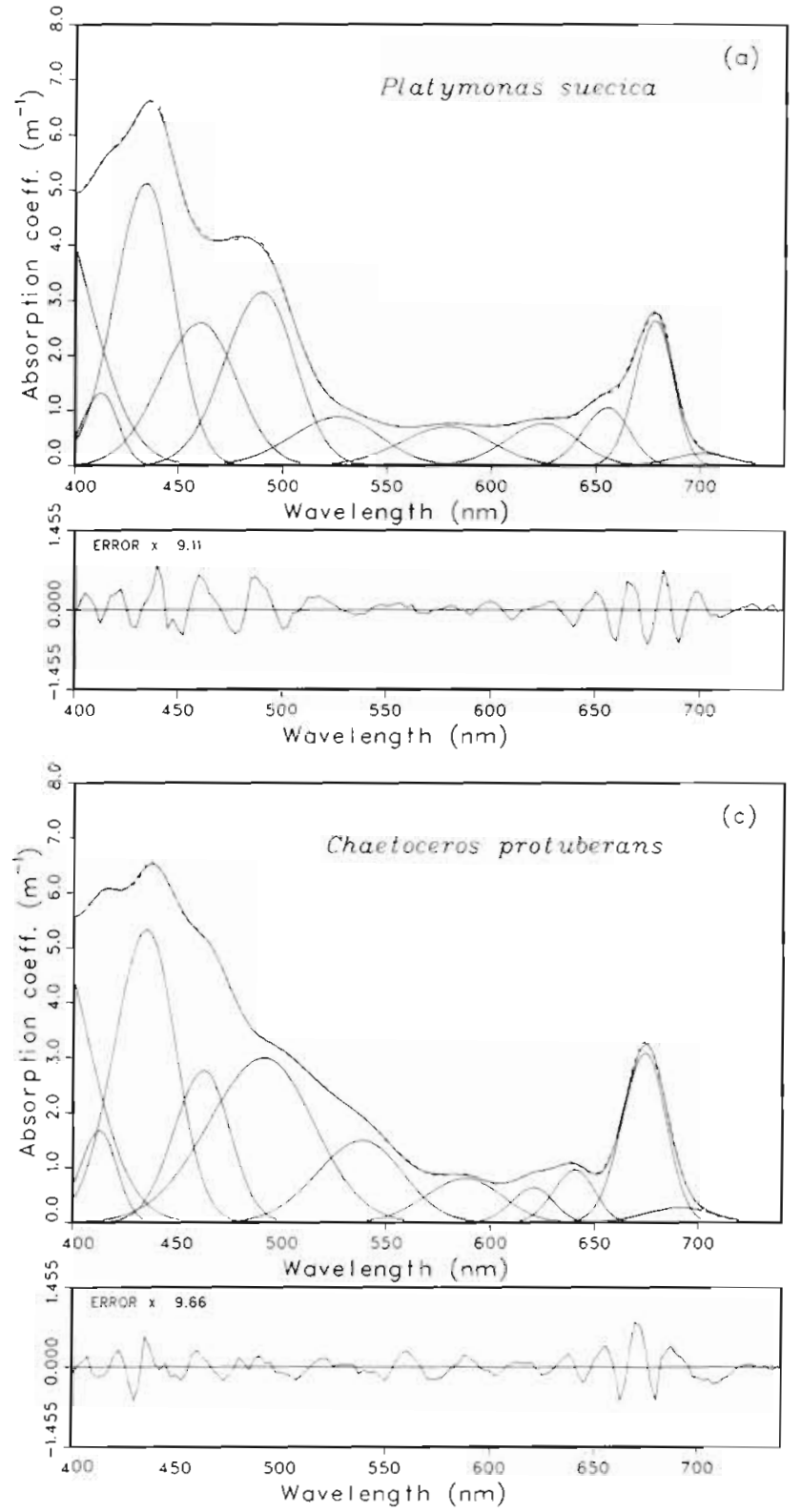
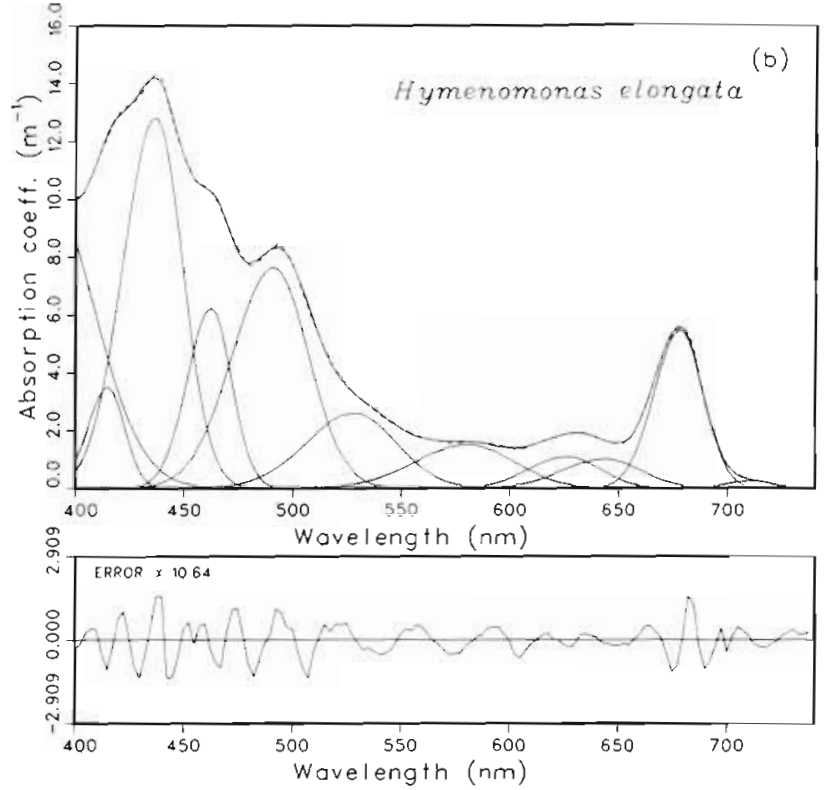

Fig. 1. Observed absorption spectra corrected for particle effect (solid line) and the corresponding fitted spectra (dashed line), expressed as the sum of 11 Gaussian components, for 3 algal cultures. (a) A chlorophycean, (b) a prymnesiophycean, (c) a diatom. The error curve (difference between observed and fitted curves) of each spectrum is shown in the lower panel. Each error curve is magnified by a number (indicated in the panel) to avoid changing the ordinate scale. A larger magnification implies a better fit

Table 2. Averaged values of wavelength positions (in $\mathrm{nm}$ ) and halfwidths (in $\mathrm{nm}$ ) of 11 Gaussian bands used to fit the absorption spectra of 3 groups of algae

\begin{tabular}{|ccccccc}
\hline Band & \multicolumn{2}{c}{ Chlorophyceae } & \multicolumn{2}{c}{ Prymnesiophyceae } & \multicolumn{2}{c}{ Diatoms } \\
& Center & Halfwidth & Center & Halfwidth & Center & Halfwidth \\
\hline 1 & 383.06 & 54.04 & 384.85 & 55.18 & 383.95 & 52.07 \\
2 & 411.72 & 23.34 & 412.63 & 21.75 & 414.03 & 18.79 \\
3 & 433.80 & 34.66 & 435.40 & 32.43 & 435.29 & 29.28 \\
4 & 463.68 & 44.96 & 462.05 & 25.65 & 460.94 & 28.71 \\
5 & 488.92 & 41.28 & 490.13 & 41.18 & 489.95 & 53.60 \\
6 & 529.92 & 47.40 & 529.53 & 45.75 & 536.33 & 44.46 \\
7 & 580.66 & 48.20 & 579.03 & 49.20 & 586.18 & 43.32 \\
8 & 623.90 & 40.42 & 623.08 & 38.50 & 623.41 & 25.99 \\
10 & 654.88 & 24.44 & 644.33 & 37.13 & 642.61 & 20.73 \\
11 & 677.80 & 19.54 & 678.03 & 23.43 & 674.09 & 21.87 \\
\hline
\end{tabular}


Table 3. Mean squares of wavelength positions and halfwidths of 11 Gaussian bands used in decomposition of the absorption spectra from 3 groups of algae

\begin{tabular}{|c|c|c|c|c|c|c|c|c|c|c|c|}
\hline \multirow{2}{*}{$\begin{array}{l}\text { Source of } \\
\text { variations }\end{array}$} & \multicolumn{11}{|c|}{ Gaussian band number } \\
\hline & 1 & 2 & 3 & 4 & 5 & 6 & 7 & 8 & 9 & 10 & 11 \\
\hline \multicolumn{12}{|l|}{ Center (in $\mathrm{nm}$ ) } \\
\hline Between groups & $3.58^{\circ}$ & 9.89 & 4.35 & $13.04 \cdots$ & 2.21 & $107.42 \cdots$ & $99.60^{\cdots}$ & 0.79 & $265.98^{\cdots}$ & $35.97 \cdots$ & $345.78^{\circ}$ \\
\hline Within groups & 0.81 & 3.28 & 1.68 & 2.05 & 1.97 & 5.85 & 7.37 & 9.24 & 1.59 & 0.21 & 22.18 \\
\hline \multicolumn{12}{|l|}{ Halfwidth (in nm) } \\
\hline Between groups & $16.55^{\cdots}$ & $39.35^{\circ}$ & $53.14^{\circ}$ & $559.86^{\cdots}$ & $378.53^{\circ} \cdot$ & $15.04 \cdots$ & $71.32 \cdots$ & $460.24^{\cdots}$ & $395.18^{\cdots}$ & $17.68^{*}$ & $211.70^{\circ}$ \\
\hline Within groups & 1.66 & 6.69 & 9.60 & 13.46 & 6.24 & 0.73 & 3.29 & 14.84 & 5.63 & 1.68 & 46.18 \\
\hline
\end{tabular}

mean squares between and within groups estimate the same variance had to be rejected for all except 4 of the band centres. In a very few cases, however, the variances of the data failed to satisfy a homogeneity criterion (Bartlett test, $p<0.01$ ). Therefore, a non-parametric method was used in parallel with the analysis of variance (Sokal \& Rohlf 1969). No differences were obtained when a Kruskal-Wallis test was used instead of a standard analysis of variances. Both methods showed a substantial 'between-group' difference for most of the bands.

For the first band, the statistical analysis (Table 3) showed a significant difference between groups in its position $(p<0.05)$ and in its halfwidth $(p<0.01)$. A multiple-range test (Tukey, $p<0.05$ ) tended to differentiate the position of this band for the Chlorophyceae from that for the Prymnesiophyceae, whereas the position for diatoms did not seem to be statistically different from that of the other 2 groups. On the other hand, the diatoms had a substantially narrower band than the other 2 groups (Table 2).

Gaussian Bands 2 and 3 were centered at 412 and $435 \mathrm{~nm}$ respectively. The analysis of variance on the position of these bands (Table 3) did not suggest any difference between the groups of algae. The halfwidths were, however, slightly different $(p<0.05)$ between diatoms (18.8 and $29.3 \mathrm{~nm}$ ) and Chlorophyceae (23.3 and $34.7 \mathrm{~nm}$ ). The Prymnesiophyceae had intermediate halfwidth values of 21.7 and $32.4 \mathrm{~nm}$ for Bands 2 and 3 , respectively, which tended to be similar to those of both the other groups.

The parameters of Band 4 were statistically very different between the groups of phytoplankton species. The position of this band was $460.9 \mathrm{~nm}$ for diatoms which was significantly different from $463.6 \mathrm{~nm}$, the position observed for the Chlorophyceae. The Prymnesiophyceae had an intermediate value of $462.1 \mathrm{~nm}$, not different from that of the other 2 groups. The halfwidth of Band 4 varied very strongly between species, being larger by a factor of 1.7 for Chlorophyceae compared with the other 2 groups (Table 2 ).
Gaussian Band 5 was centered at $490 \mathrm{~nm}$ and this position did not seem to be influenced by taxonomic group. Its halfwidth, however, varied significantly between the algal groups, with the diatoms having a slightly larger band (53.6 nm) than the Chlorophyceae and the Prymnesiophyceae (41.3 and $41.2 \mathrm{~nm}$ respectively). Gaussian Bands 6 and 7 were located in the region of minimum light absorption by phytoplankton cells. They were centered at 529.7 and $579.9 \mathrm{~nm}$ respectively for both the Chlorophyceae and the Prymnesiophyceae, whereas the diatoms tended to absorb at a longer wavelength in both cases $(536.3$ and $586.2 \mathrm{~nm}$ for Bands 6 and 7 respectively). The statistical analysis on the halfwidths suggested a different behavior of these bands between groups. Indeed, each of the 3 algal groups presented a significantly different halfwidth for Band 6, ranging from 44.5 to $47.4 \mathrm{~nm}$ (Table 2). On the other hand, Band 7 was significantly narrower for diatoms $(43.3 \mathrm{~nm})$ than for the other 2 groups ( $48.7 \mathrm{~nm}$ on average).

No difference between groups was observed in the position of Gaussian Band 8, centered at $623.5 \mathrm{~nm}$. This band had a small peak but was proportionately very broad. As with the previous band, its halfwidth was significantly narrower for the diatoms $(26.0 \mathrm{~nm})$ than for the other 2 groups (40.4 and $38.5 \mathrm{~nm}$ for Chlorophyceae and Prymnesiophyceae respectively).

The parameters of the absorbing Bands 9 and 10 showed significant differences between the groups of algae. Band 9 was centered at $643.5 \mathrm{~nm}$ on average for the diatoms and for the Prymnesiophyceae, which is 10 nm less than the position for the Chlorophyceae (654.9 $\mathrm{nm})$. The halfwidths were significantly different for each of the 3 groups, varying from $20.8 \mathrm{~nm}$ to $37.1 \mathrm{~nm}$ (Table 2). The difference in the position of Band 10 was not so large. Diatoms presented a peak absorption at $674.1 \mathrm{~nm}$, which differed from the corresponding peak in the other groups by only $4 \mathrm{~nm}$. The halfwidth was narrower for Chlorophyceae than for the other 2 groups (Table 2).

Finally, the last absorbing component of the spectra 
is represented by Gaussian Band 11, of low amplitude. Its position ranged from 692 to $706 \mathrm{~nm}$, with a significant difference between diatoms $(692.0 \mathrm{~nm})$ and the other 2 groups (700.8 and $706.3 \mathrm{~nm}$ ). On the other hand, its halfwidth tended to differentiate the Prymnesiophyceae $(27.5 \mathrm{~nm})$ from the diatoms $(39.2 \mathrm{~nm})$, while the Chlorophyceae had an intermediate value of $33.6 \mathrm{~nm}$, not significantly different from the other 2 groups.

\section{DISCUSSION}

Previous studies using curve decomposition methods were concerned mainly with the absorption properties of the chlorophylls in the red part of the spectrum. The results showed the complexity of the pigment system in algae and higher plants, in which the absorption maximum of chlorophyll at 670 to $680 \mathrm{~nm}$ could be the result of 6,10 or even more absorbing components (Katz et al. 1977 and references therein). A more simplistic view of the light-harvesting system in algae, such as the one presented here, has the advantage of ease of use in ecological applications such as estimation of the optical properties of natural phytoplankton communities and their variation in time and space. Nevertheless, the efficiency of the present model and the associated statistical data must be tested on some physiological basis.

\section{Biological interpretation of Gaussian bands}

The first band has a maximum absorption in the UV range of the spectrum. Physiologically, such a strongly absorbing band is likely to include several components, starting with the absorption by the particulate material itself (i.e., the non-photosynthetic pigments). The absorption spectra of natural communities of phytoplankton, after pigment extraction, often display a monotonous increase from the red to the blue regions of the light spectrum (Kishino et al. 1984), similar to the absorption spectra of detritus or yellow substances. Also, some recent studies (Yentsch \& Phinney 1989) have demonstrated the presence of mycosporine-like UV-absorbing pigments in significant amounts within several algal species commonly found in the marine environment.

Gaussian Bands 2, 3,8 and 10 with their maxima at $412,435,623$ and $675 \mathrm{~nm}$ respectively correspond to in vivo absorption by chl a. Goedheer (1970) observed that the in vivo absorption spectrum of the brown benthic alga Laminaria digitata had chl a peaks at 418 , 437, 618 and $673 \mathrm{~nm}$. Similarly, the absorption spectrum of P700-chla-protein complex from Glenodinium sp. (Prézelin 1980) showed peaks and shoulders at 419 437,618 and $675 \mathrm{~nm}$. Owens \& Wold (1986) found that the presence of chl a in different pigment-protein complexes was indicated by absorption at 418,440 and 670 to $678 \mathrm{~nm}$. The statistical analysis of our data suggests less significant differences between groups for these bands, in agreement with the ubiquitous properties of chl a in autotrophic organisms. Band 10 represents a particular case in the sense that, for the diatoms, the chl a absorption in the red seems to be shifted significantly to a shorter wavelength $(674 \mathrm{~nm})$ than for the other 2 groups $(678 \mathrm{~nm})$. Such a difference can be explained by a variation between groups of algae in the ratio of the photosystem I (PSI) to the photosystem II (PSII). The red absorption band of photosynthetic reaction center PSII occurs at shorter wavelengths (670 to $675 \mathrm{~nm}$ ) when compared with the position of the absorption band associated with the PSI reaction center ( 677 to $680 \mathrm{~nm}$ ) (Larkum \& Barrett 1983). A change in the ratio of PSI to PSII should then induce a slight variation in the wavelength position of the chl a absorption maximum. Falkowski et al. (1981) observed a PSI:PSII ratio of ca 1 for the Chlorophyceae, whereas the ratio was found to be only 0.44 in diatoms. The red absorption maximum of chl a for diatoms would then be shifted to shorter wavelengths compared with Chlorophyceae. It is also very likely that this ratio may vary in response to other factors, such as environmental light conditions (Melis \& Brown 1980, Owens 1986).

The parameters of Bands 4 and 9 correspond to the absorption characteristics of other groups of chlorophylls, particularly chl $b$ for Chlorophyceae and chl $c$ for diatoms and Prymnesiophyceae. The 2 types of algae cannot be differentiated on the basis of the position of the absorption band in the blue. On the other hand, the halfwidth of Band 4 differs very significantly ( $p<<0.01$ ) between the groups of algae, with the cells containing chl $c$ having a much narrower band than the Chlorophyceae. A broad absorption band for chl $b$ should allow Chlorophyceae and other cells containing chl $b$ to utilize blue light with high efficiency. In this context, it is interesting to note that Chlorophyceae and Prasinophyceae are now generally considered to contribute to a high proportion of ultraphytoplankton in the deep chlorophyll maximum of oligotrophic oceans (Gieskes \& Kraay 1986, Hooks et al. 1988). In the red part of the spectrum, the wavelength position of Band 9 varies by $10 \mathrm{~nm}$ between Chlorophyceae (655 nm) and the other 2 groups (643 and $644 \mathrm{~nm}$ ). The results are in complete agreement with absorption spectra of pigment-protein complexes containing chl $b$ (Prézelin \& Boczar 1986, Fawley et al. 1990) and chl c (Friedman \& Alberte 1984, 1986, Owens \& Wold 1986, Rhiel et al. 1987, Boczar \& Prézelin 1989).

Absorption Bands 5 and 6 on the decomposed 
spectra correspond to absorption by carotenoids. The position of Band 5 seems to be common to the 3 groups of algae, whereas Band 6 is positioned at a longer wavelength for the diatoms $(536 \mathrm{~nm})$ than for the other groups (529 and $530 \mathrm{~nm}$ ). From this result, it is tempting to identify Bands 5 and 6 as representative, respectively, of the carotene and the xanthophyll groups of pigments. Indeed, carotenes, and particularly $\beta$ carotene, are present in most algal taxa (Rowan 1989). Also, the presence of $\beta$-carotene in the absorption spectra of pigment-protein complexes is indicated by a shoulder at 485 to $495 \mathrm{~nm}$ (Thornber \& Alberte 1977. Boczar \& Prézelin 1989). On the other hand, the hypothesis that xanthophylls are responsible for Band 6 is supported by the work of Owens \& Wold (1986), who pointed out that an increase in the background absorption within the 480 to $550 \mathrm{~nm}$ range on the absorption spectra of pigment-protein complexes of diatoms was attributable to fucoxanthin. They also noticed a large decrease in absorption at these wavelengths for P700chla-protein complex and chla-chlc light harvesting complex, both containing very little or no fucoxanthin but having some $\beta$-carotene, as indicated by a shoulder at $490 \mathrm{~nm}$. Fucoxanthin was also detected in the in vivo absorption spectrum of Laminaria digitata as a feature at 530 to $545 \mathrm{~nm}$ (Goedheer 1970). Such a differentiation between carotenes and xanthophylls, although an attractive idea, may be too simplistic. In fact, up to 500 carotenoids occur naturally (Liaaen-Jensen \& Andrewes 1985) and all of them absorb light within the 400 to $550 \mathrm{~nm}$ region. Their absorbing properties are known to change with some differences in their chemical structure, such as the number of double bonds and the degree of cyclisation (Britton 1983). Although xanthophylls differ from carotenes by the presence of oxygenated groups in their molecules, such a factor is not sufficient to distinguish specifically the absorption properties of the 2 types of pigments. Therefore, both Bands 5 and 6 may very well correspond to the absorption of light by a mixture of carotenes and xanthophylls.

The small Gaussian Band 7 contributes to the optical properties of phytoplankton in the region of minimum absorption. Its position varies from 579 to $586 \mathrm{~nm}$ according to species. Such a band may represent a small absorbing component of the chlorophylls. The presence of a small feature at $585 \mathrm{~nm}$ due to chl $c$ was observed in the in vivo absorption spectrum of Laminaria digitata (Goedheer 1970). The same feature was observed in some absorption spectra of chla-chlcprotein complexes (Rhiel et al. 1987, Boczar \& Prézelin 1989). On the other hand, chl a may also contribute to absorption in that region of the spectrum. Prézelin (1980) and Fawley et al. (1990) observed a slight absorption at 470 to $600 \mathrm{~nm}$ in the spectra of P700-chlaprotein complexes. An in vivo spectrum of Nanno- chloris salina, containing neither chl $b$ nor chl $c$, also showed an absorption at around $580 \mathrm{~nm}$ due to chl a (Owens et al. 1987).

Band 11 does not have a clear physiological explanation. The decomposition of the chl a peak in the red by French et al. (1972) produced a similar unexplained Gaussian component with a peak position varying from 700 to $706 \mathrm{~nm}$. Later, Katz et al. (1977) postulated that all chlorophyll structures absorbing at $685 \mathrm{~nm}$ and higher wavelengths are mainly the results of different interactions between the chl a molecules and other compounds such as water or phaeophytins.

\section{Specific absorption coefficients}

A non-linearity in the relationship between the absorption coefficient $a_{p}(\lambda)$ and the concentration of chl a has often been observed in natural environments, particularly at low chlorophyll concentrations (Prieur \& Sathyendranath 1981, Kiefer \& Soohoo 1982, Yentsch \& Phinney 1989). Such a discontinuity has been related either to the particle effect, the pigment composition effect, or a combination of both.

In the present study, the relationship between the height of each Gaussian band and the pigment concentration to which it corresponds is expected to be linear since the particle effect and the differences in pigment composition have been successively removed from the initial absorption spectra. In Figs. 2, 3, 4, 5, a linear fit has been applied to the data. In most cases, the fitted
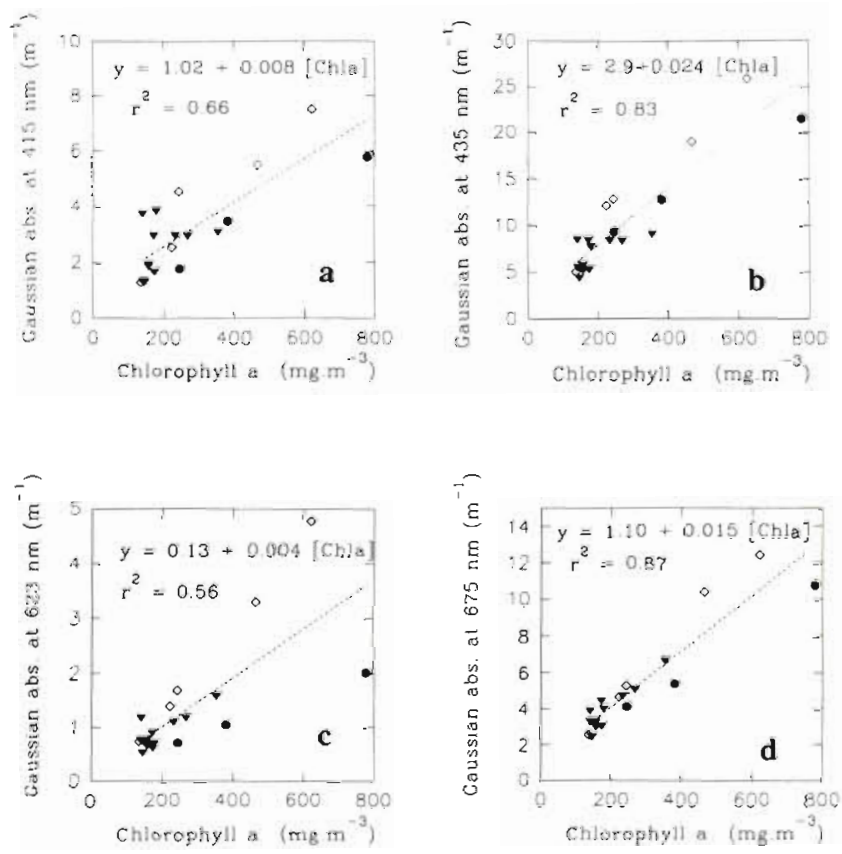

Fig. 2. Gaussian band height at (a) $415 \mathrm{~nm}$, (b) $435 \mathrm{~nm}$, (c) 623 $\mathrm{nm}$ and (d) $675 \mathrm{~nm}$ vs chlorophyll a concentration. (v)

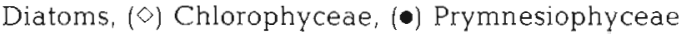



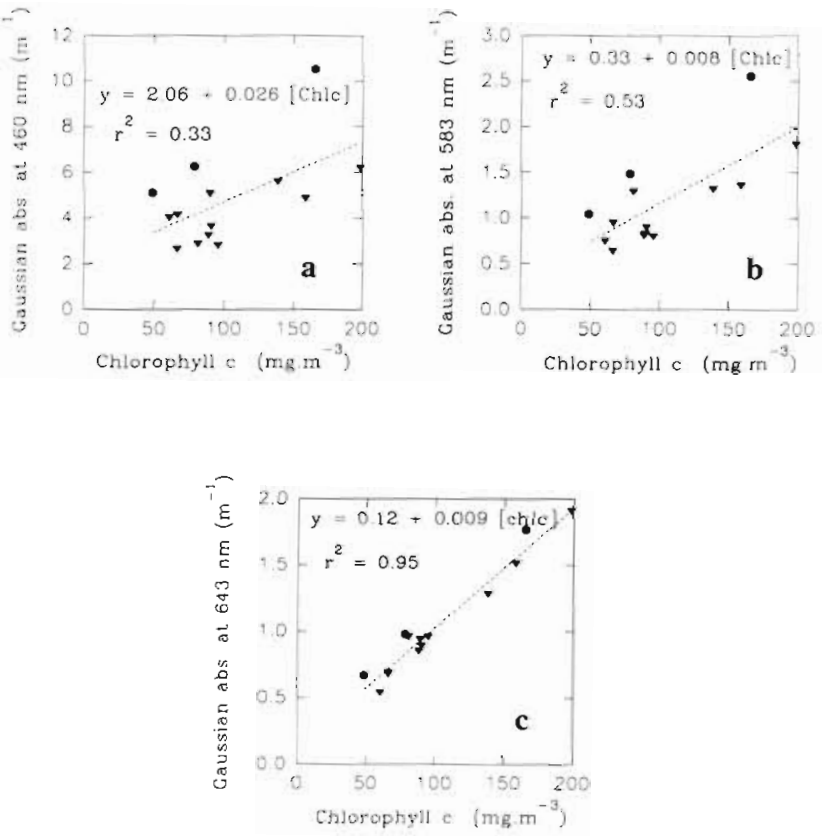

Fig. 3. Gaussian band height at (a) $460 \mathrm{~nm}$, (b) $583 \mathrm{~nm}$ and (c) $643 \mathrm{~nm}$ vs chlorophyll $\mathrm{c}$ concentration. Symbols as in Fig. 2

curves explained more than $80 \%$ of the variances and the correlations were significant at the 0.01 probability level. Note that here, the linearity is maintained for a multi-species sample set. Until now, a linear relationship had been observed between the absorption coefficient $a_{p}(\lambda)$ and the concentration of chl a on only monospecific algal cultures (Sathyendranath et al. 1987).

An increase in the scatter amongst the data points was observed with the low-amplitude Gaussian bands (Figs. 2a, c, 3b). In these particular cases, the linear fit still explains more than $50 \%$ of the variances but the data were probably affected by covarying absorption by more than 1 pigment, which failed to be separated by the method. For example, it has already been mentioned that Band 7 (Fig. 3b) most likely included absorption by chl $c$ as well as a small contribution from chl a. A multiple regression analysis describes the relationship between the height of Band $7(y)$ and the concentrations of chl $a$ and $c$ as follows:

$$
y=0.26+0.003 C_{\text {chlc }}+0.002 C_{\text {chla }}
$$

with a regression coefficient $r^{2}$ of 0.89 . At these low levels of absorption, the data might also be affected by instrumental noise.

A linear relationship between the Gaussian absorption at $460 \mathrm{~nm}$ and chl c concentration (Fig. 3a) explained only $33 \%$ of the variances, but the correlation was still significant at the 0.05 probability level. Note, in this case, that the data points representing the Prymnesiophyceae tend to lie above the regression line
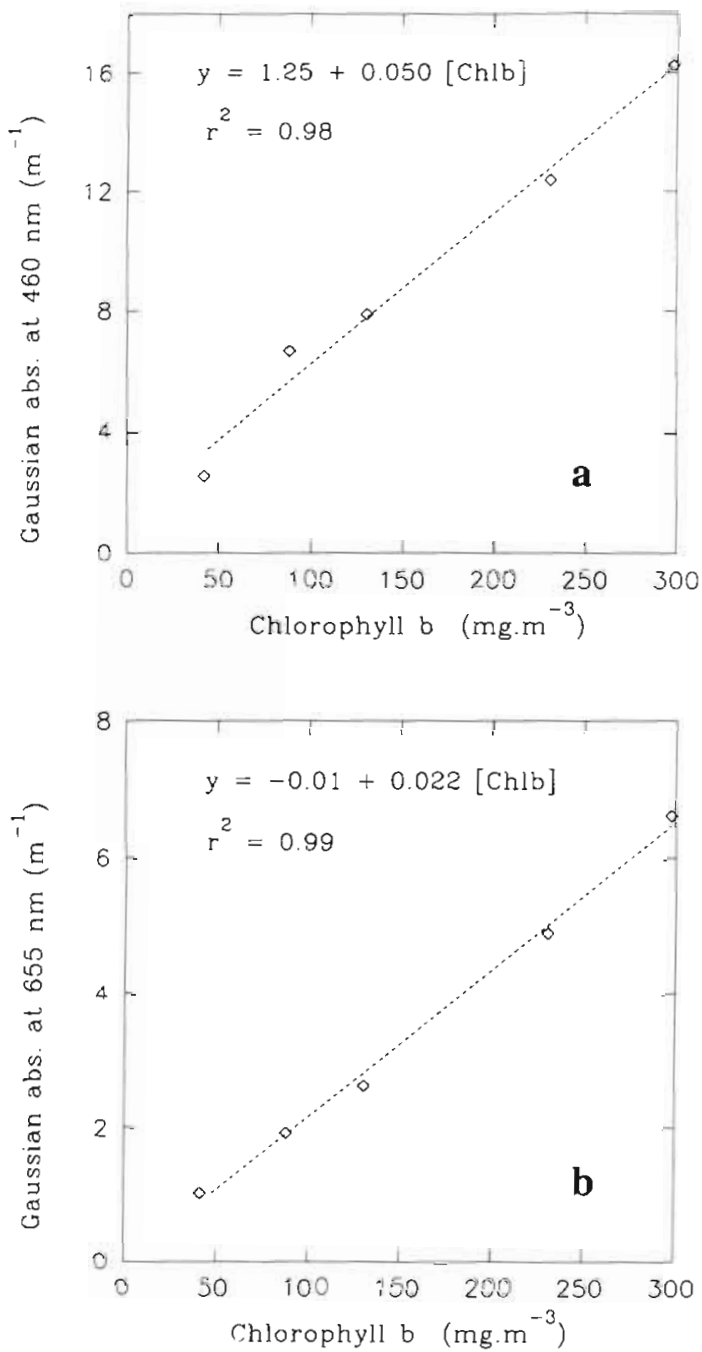

Fig. 4. Gaussian band height at (a) $460 \mathrm{~nm}$ and (b) $655 \mathrm{~nm}$ vs chlorophyll $b$ concentration

and above the data obtained for diatoms. The same trend is maintained in Fig. 3b, c. Most of the diatoms, particularly the species used in the present study, are known to contain chl $c_{1}$ and $c_{2}$ (Stauber \& Jeffrey 1988). In addition to these 2 pigments, the Prymnesiophyceae have a third form, chl $c_{3}$, which possesses slightly different optical properties (Fawley 1989). This difference may explain the higher absorption coefficient of Prymnesiophyceae when compared with that of diatoms. As a result, the regressions in Fig. 3 are probably biased by the preponderance of diatoms. We corrected for this effect by using the geometric regression line whose slope is given by the ratio of the actual slope to the correlation coefficient (Ricker 1984). This procedure gave a value of $\left(a^{\prime}{ }_{c h l c}\right)$ at $460 \mathrm{~nm}$ of $0.045 \mathrm{~m}^{2}$ $\mathrm{mg}^{-1} \mathrm{chl} c$.

The true specific absorption of chl a at $435 \mathrm{~nm}$ is given in Fig. $2 b$ by the slope of the regression line. Note 

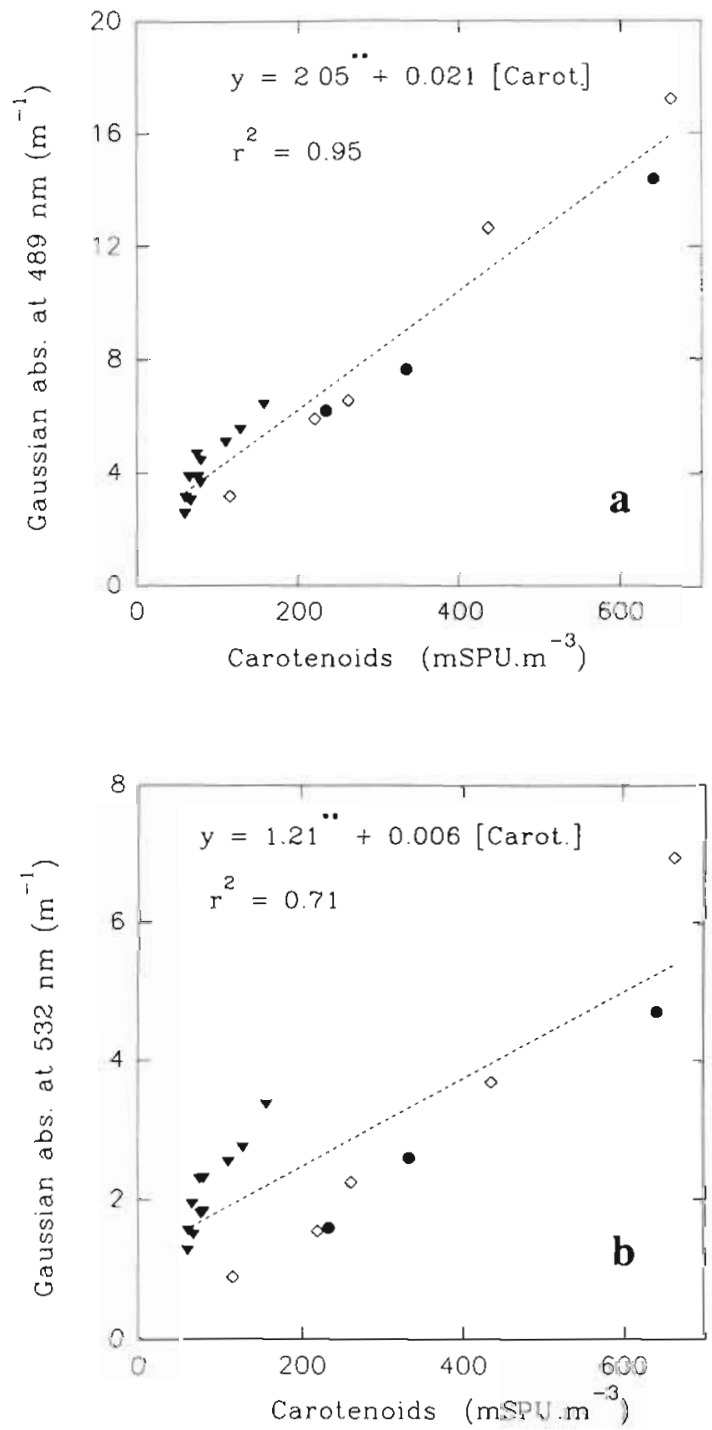

Fig. 5. Gaussian band height at (a) $489 \mathrm{~nm}$ and (b) $532 \mathrm{~nm}$ vs carotenoids concentration. (') Indicates an intercept significantly different from 0 ; other symbols as in Fig. 2

that the 'true', in vivo specific absorption coefficient of chl $a$, after correction for particle effect, has not been reported previously in the literature. For this reason, comparisons with the 'apparent' value $a^{*}$ reported so far in the literature have to be made with caution. Nevertheless, the specific absorption coefficient obtained from Fig. 2b fits well within the wide range of values given in the literature for the apparent specific absorption coefficient of chl $a$ in the blue region (Maske \& Haardt 1987, Sathyendranath et al. 1987, Mitchell \& Kiefer 1988). The present decomposition method suggests that the high variability in $a^{\circ}$ at 435 to $440 \mathrm{~nm}$ depends on the species involved. The decomposition of absorption spectra from Chlorophyceae (Fig. 1a) showed that chl $b$ contributes to a high pro- portion (ca 30 to $35 \%$ ) of the total absorption of the cells at 435 to $440 \mathrm{~nm}$. This explains why $a^{*}$ obtained from Chlorophyceae cultures (e.g. Table 4 in Mitchell \& Kiefer 1988) would be systematically higher than the $a^{\prime}$ chia value proposed here. On the other hand, the contribution to total absorption at 435 to $440 \mathrm{~nm}$ by pigments other than chl $a$ is less in the case of diatoms and prymnesiophyceae (Fig. 1). Again, it explains why the apparent values of $a^{*}$ for cells containing chl $c$ (e.g. Mitchell \& Kiefer 1988) become more similar to $a_{\text {chla }}^{\prime}$.

In the red part of the spectrum, the particle effect is not as important as at shorter wavelengths where the absorption is higher (Kirk 1983). On the other hand, the contribution to total absorption at $675 \mathrm{~nm}$ by pigments other than chl a is minimal (Fig. 1). As a result, the range of values for $a^{*}$ at $675 \mathrm{~nm}, 0.010$ to $0.030 \mathrm{~m}^{2} \mathrm{mg}^{-1}$ chl a (Maske \& Haardt 1987. Bricaud et al. 1988) is much narrower than for $a^{*}$ in the blue region and tends on average to become reconciled with the present value for $a_{\text {chla }}^{\prime}$ of $0.015 \mathrm{~m}^{2} \mathrm{mg}^{-1} \mathrm{chl} \mathrm{a} \mathrm{(Fig.} \mathrm{2d).}$

The decomposition of absorption spectra also gives the true specific absorption coefficient of chl b (Fig. 4) and carotenoids (Fig. 5) at their wavelengths of maximum absorption. The intercepts of the regression lines relating absorption Bands 5 and 6 to the carotenoid concentrations (Fig. 5) were significantly different from zero. Problems with carotenoids, however, are not unexpected, considering the imprecise method used to measure their concentrations (Parsons et al, 1984).

Regression analysis should give the specific absorption coefficient for each band. However, the technique of least-square analysis tends to assign more weight to the data points that are most distant from the origin. To avoid this effect, we prefer to use the specific absorption coefficient as computed by the mean of the specific absorption coefficient calculated for each sample. These values for each of the 4 pigments considered in the present work are shown in Table 4 . The absorption of the first and last bands has been normalized to chl a since the heights of both bands showed a good correlation with the concentration of this pigment $\left(\mathrm{r}^{2}=0.84\right.$ and 0.87 ).

\section{Reconstruction of in vivo absorption spectrum}

From the present analysis, it is possible to recover the entire absorption spectrum of any phytoplankton sample. Such reconstruction will be based on the sum of several Gaussian curves:

$$
a_{p}(\lambda)=\sum_{i=1}^{n} \alpha_{\lambda}^{\prime}\left(\lambda_{m i}\right) C_{l} \exp \left[-\frac{\left(\lambda-\lambda_{m\lrcorner}\right)^{2}}{2 W_{i}^{2}}\right]
$$


Table 4. Mean characteristics of the Gaussian bands. Chl: chlorophyll; carot: carotenoids; Spec. abs. coeff. specific absorption coefficient

\begin{tabular}{|c|c|c|c|c|c|c|c|c|c|c|c|c|c|}
\hline \multirow[t]{2}{*}{ Characteristic } & \multicolumn{13}{|c|}{ Gaussian band number and associated pigment species } \\
\hline & $\begin{array}{c}1 \\
\text { Chl } a\end{array}$ & $\begin{array}{c}2 \\
\mathrm{Chl} a\end{array}$ & $\begin{array}{c}3 \\
\text { Chl a }\end{array}$ & $\begin{array}{c}4 \mathrm{c}^{\mathrm{d}} \\
\mathrm{Chl} \mathrm{C}\end{array}$ & $\begin{array}{c}4 b^{2} \\
\text { Chl b }\end{array}$ & $\begin{array}{c}5 \\
\text { Carot. }\end{array}$ & $\begin{array}{c}6 \\
\text { Carot. }\end{array}$ & $\begin{array}{c}7^{b} \\
\mathrm{Chl} c\end{array}$ & $\begin{array}{c}8 \\
\text { Chl a }\end{array}$ & $\begin{array}{c}9 \mathrm{c}^{\mathrm{a}} \\
\mathrm{Chl} \mathrm{c}\end{array}$ & $\begin{array}{c}9 b^{a} \\
C h l b\end{array}$ & $\begin{array}{c}10 \\
\text { Chl a }\end{array}$ & $\begin{array}{c}11 \\
\text { Chl a }\end{array}$ \\
\hline Spec. abs. coeff. ${ }^{c}$ & 0.037 & 0.012 & 0.039 & 0.051 & 0.061 & 0.038 & 0.017 & 0.012 & 0.005 & 0.010 & 0.022 & 0.020 & 0.002 \\
\hline Halfwidth (nm) & 53.8 & 21.3 & 32.1 & 27.2 & 45.0 & 45.4 & 45.9 & 46.3 & 35.0 & 28.9 & 24.4 & 21.6 & 33.5 \\
\hline Center (nm) & 384 & 413 & 435 & 461 & 464 & 490 & 532 & 583 & 623 & 644 & 655 & 676 & 700 \\
\hline \multicolumn{14}{|c|}{ 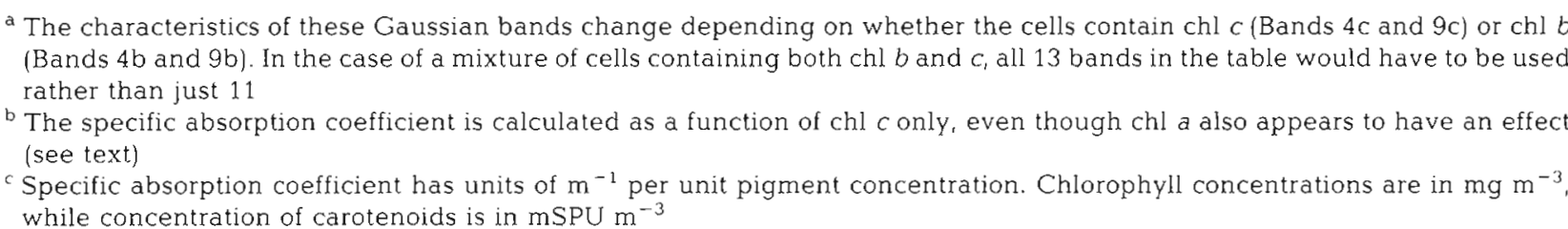 } \\
\hline
\end{tabular}

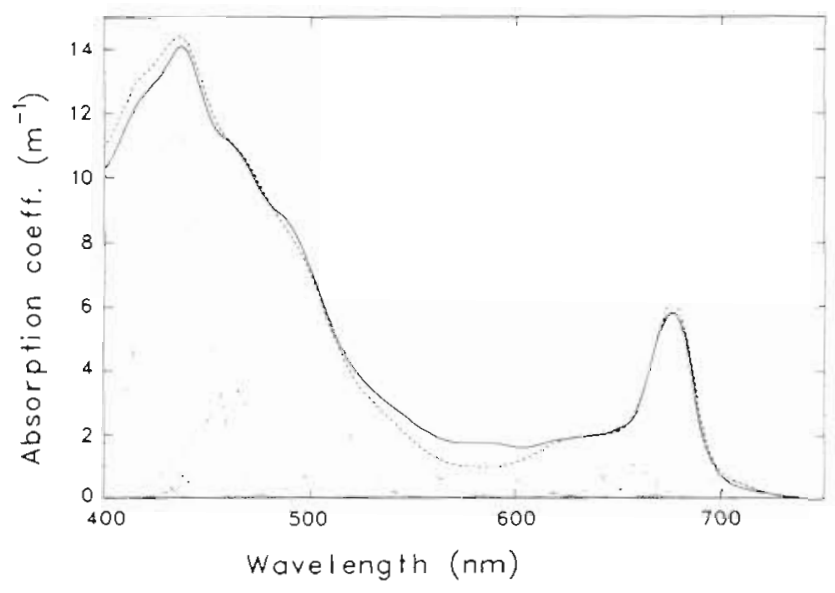

Fig. 6. Reconstruction of in vivo absorption spectrum of a phytoplankton sample (solid line) containing diatoms, Chlorophyceae and Prymnesiophyceae. The fitted spectrum (dashed line) has been estimated by the sum of 13 Gaussian bands which represent the absorption properties of the major pigment groups in the cells

where $C_{1}$ is the concentration of the pigment responsible for the ith Gaussian band, $\lambda_{m !}$ is the position of maximum absorption for that band, $W_{1}$ represents the halfwidth of the Gaussian curve, and $a_{i}^{\prime}\left(\lambda_{m i}\right)$ is the mean specific absorption coefficient for the ith component at $\lambda_{m i}$. Fig. 6 illustrates the reconstructed absorption spectrum of a population containing Chlorophyceae, diatoms and Prymnesiophyceae. The observed absorption spectrum has been made up by averaging the absorption spectra of the 20 algal cultures used in the present study (always after correction for particle effect). In the same way, the concentrations of the major pigments were averaged over the values for the 20 cultures (Sathyendranath et al. 1987). The resulting spectrum represents the absorption properties of cells containing both $c h l b$ and chl $c$. In the decomposition of spectra of monospecific cultures, Bands 4 and 9 were used to represent either chl $b$ or chl $c$. However, since both these pigments are present in the mixture of species considered here, we used 13 bands in this reconstruction instead of the 11 used for individual species. Each band is characterized by the parameters in Table 4, where we have given average characteristics for each pigment, ignoring inter-specific differences.

The reconstructed absorption spectrum closely matches the observed curve. Slight differences occur in the region of minimum absorption, where the estimated absorption coefficient is systematically lower than the observed values. This discrepancy probably results from an underestimation of the height of Band 7 . which was computed using the concentrations of only chl $c$.

\section{CONCLUSION}

The present study has shown that the in vivo absorption spectra of phytoplankton cells, after correction for the particle effect, can be represented as the sum of a dozen or so Gaussian absorption bands. Linear correlation of the different peak heights with the concentrations of any one of the 4 major pigments in the samples indicates that the method has been successful in separating the absorptions due to each pigment. One exception to this is the small absorption band at the 579 to $586 \mathrm{~nm}$ region, which appears to be influenced by both chl a and chl c. The role of UVblue absorbing material appears to be non-negligible in the samples, but we are unable to propose a specific absorption coefficient other than one normalized to chl a for the Gaussian peak associated with this absorption, since no measurements were made of the concentrations of the pigments that may be responsible for this absorption. 
The relationship between peak heights and pigment concentrations are hardly affected by the phytoplankton species. This may be considered an indication of the validity of the simple model of particle effect applied to the data set: if this effect had not been corrected for adequately, the consequence would have been a greater dispersion between the results for different species. On the other hand, some interspecific differences in peak characteristics were noted, especially in the peak positions and in the bandwidths. These differences, however, can be explained in terms of the known variations in pigment composition from species to species. Note that the possibility exists that these differences could be exploited in the identification of major phytoplankton species present in a natural sample from an analysis of its absorption spectrum. Admittedly, the problem would become more complicated, the greater the number of species present in the sample.

The cultures used in the present study cover 3 major phytoplankton groups, but the list is by no means exhaustive, and future studies would be necessary to extend the results to other groups. One of the important groups that remain to be studied is of course the marine cyanobacteria, known to be abundant in oligotrophic waters.

We have presented here the first estimates of the 'true' in vivo specific absorption coefficients of 4 major pigments, after correction for particle effect. This opens the possibility of estimating the absorption spectrum of a phytoplankton sample from measurements of its pigment concentrations and cell size. With the advent of the modern techniques of flow cytometry and HPLC, the measurements required for application of these results are becoming increasingly common. The method proposed for estimating the absorption spectrum of phytoplankton is indirect, but has the advantage that it circumvents the problem of separating absorption by live phytoplankton from background absorption by covarying substances. This method is also free of some of the pitfalls of other methods that have been proposed, such as the problem of obtaining measurements on a representative sample set for microphotometry (Iturriaga \& Siegel 1989), and the problem of quantifying the results from the filter technique of Yentsch (1962) and Mitchell \& Kiefer (1984). The analysis presented here is based on estimates of pigment concentrations from the absorption spectra of acetone extracts. We do not yet know how well these results would apply to concentration data estimated by other techniques, for example the HPLC method. But we anticipate that in the future, as more accurate HPLC measurements become more routine, they will facilitate refinement of the results presented here.
Acknowledgements. The authors thank Dr Trevor Platt for continued help and encouragement during this work, and for useful suggestions and comments on the manuscript. We are very grateful to $\mathrm{Dr}$ Gienn A. Ford /Carnegie Institute of Washington) who gave us a copy of the RESOLV program of curve decomposition. We thank Ms Cathy J. Porter for her assistance in the computer work. The manuscript also benefited from the comments of 3 anonymous reviewers. This work was supported by the Office of Naval Research, the National Aeronautics and Space Administration, USA, and the Dept of Fisheries and Oceans, Canada. Additional support was provided by the Natural Sciences and Engineering Research Council through an Operating Grant to S.S.

\section{LITERATURE CITED}

Bidigare, R. R., Smith, R. C., Baker, K. S., Marra, J. (1987) Oceanic primary production estimates from measurements of spectral irradiance and pigment concentrations. Global biogeochem. Cycles 1-171-186

Boczar, B. A., Prézelin, B. B. (1989). Organization and comparison of chlorophyll-protein complexes from two fucoxanthin-containing algae: Nitzschia closterium (Bacillariophyceae) and Isochrysis galbana (Prymnesiophyceae). Pl. Cell Physiol. 30: 1047-1056

Bohren, C. F., Huffman, D. R. (1983). Absorption and scattering of light by small particles. John Wiley \& Sons Inc., New York

Bricaud, A., Bédhomme, A.-L., Morel, A. (1988). Optical properties of diverse phytoplanktonic species: experimental results and theoretical interpretation. J. Plankton Res. 10: $851-873$

Bricaud, A., Morel, A. (1986), Light attenuation and scattering by phytoplanktonic cells: a theoretical modeling. Appl. Optics 25: 571-580

Britton, G. (1983). The biochemistry of natural pigments. Cambridge University Press, Cambridge

Cotton, T M., Trifunac, A. D., Ballschmiter, K., Katz, J. J. (1974). State of chlorophyll a in vitro and in vivo from electronic transition spectra, and the nature of antenna chlorophyll. Biochim. biophys. Acta 368: 181-198

Dubinsky Z. Falkowski, P. G., Wyman, K. (1986). Light harvesting and utilization by phytoplankton. Pl. Cell Physiol. 27: $1335-1349$

Duysens, L. M. N. (1956). The flattening effect of the absorption spectra of suspensions as compared to that of solutions. Biochim. biophys. Acta 19: 1-12

Falkowski, P. G., Owens, T G., Ley, H. C., Mauzerall, D. C. (1981). Effects of growth irradiance levels on the ratio of reaction centers in two species of marine phytoplankton. Pl. Physiol. 68: 969-973

Fawley, M. W. (1989). Detection of chlorophylls $c_{1}, c_{2}$ and $c_{3}$ in pigment extracts of Prymnesium parvum (prymnesiophyceae). J. Phycol. (1989) 25: 601-604

Fawley, M. W., Douglas, C. A., Stewart, K. D., Mattox, K. R. (1990). Light-harvesting pigment-protein complexes of the ulvophyceae (Chlorophyta): characterization and phylogenetic significance. J. Phycol. 26: 186-195

Förster, T. (1965). Delocalized excitation and excitation transfer. In: Sinanoğlu, O. (ed.) Modern quantum chemistry 3. Academic Press, New York, p. 93-137

French, C. S., Brown, J. S., Lawrence, M. C. (1972). Four universal forms of chlorophyll a. Pl. Physiol. 49: 421-429

French, C. S., Brown, J S., Prager, L., Lawrence, M. C. (1967). Analysis of spectra of natural chlorophyll complexes. Carnegie Inst. Washington, Yearb. $67 \cdot 536-546$ 
Friedman, A. L., Alberte, R. S. (1984). A diatom light-harvesting pigment-protein complex. Purification and characterization. Pl. Physiol. 76: 483-489

Friedman, A. L., Alberte, R. S. (1986). Biogenesis and light regulation of the major light harvesting chlorophyll-protein of diatoms. Pl. Physiol. 80: 43-51

Gieskes, W. W. Kraay, G. W (1986). Floristic and physiological differences between the shallow and the deep nanophytoplankton community in the euphotic zone of the open tropical Atlantic revealed by HPLC analysis of pigments. Mar. Biol. 91: 567-576

Goedheer, J. C. (1970). On the pigment system of brown algae. Photosynthetica 4: 97-106

Gordon, H. R., Morel, A. (1983). Remote assessment of ocean colour for interpretation of satellite visible imagery. A review. Lecture notes on coastal and estuarine studies, Vol. 4. Springer-Verlag, New York

Hooks, C. E., Bidigare, R. R., Keller, M. D., Guillard, R. R. L. (1988). Coccoid eukaryotic marine ultraplankters with four different HPLC pigment signatures. J. Phycol. 24: 571-580

Iturriaga, R., Siegel, D. A. (1989). Microphotometric characterization of phytoplankton and detrital absorption properties in the Sargasso Sea. Limnol. Oceanogr. 34:1706-1727

Kamykowski, D. (1987). A preliminary biophysical model of the relationship between temperature and plant nutrients in the upper ocean. Deep Sea Res. 7: 1067-1079

Katz, J. J., Norris, J. R., Shipman, L. L. (1977). Models for reaction-center and antenna chlorophyll. Brookhaven Symp. Biol. 28: 16-55

Kiefer, D. A., Soohoo, J. B. (1982). Spectral absorption by marine particles of coastal waters of Baja California. Limnol. Oceanogr. $27 \cdot 492-499$

Kirk, J T. O. (1975). A theoretical analysis of the contribution of algal cells to the attenuation of light within natural waters. I. General treatments of suspensions of living cells. New Phytol. 75: 1-20

Kirk, J. T O. (1983). Light and photosynthesis in aquatic ecosystems. Cambridge University Press, Cambridge

Kishino, M., Booth, C. R., Okami, N. (1984). Underwater radiant energy absorbed by phytoplankton, detritus, dissolved matter, and pure water. Limnol. Oceanogr 29: $340-349$

Knox, R. S. (1963). Theory of excitons. In: Seitz, F., Turnbull, D. (eds.) Solid state physics. Academic Press, London

Larkum, A. W D., Barrett, J. (1983). Light-harvesting processes in algae. In: Woolhouse, $H$. W (ed.) Advances in botanical research. Academic Press, New York, p. 1-219

Lewis, M. R., Cullen, J. J., Platt, T (1983). Phytoplankton and thermal structure in the upper ocean: consequences of nonuniformity in chlorophyll profile. J geophys. Res. $88(\mathrm{C} 4): 2565-2570$

Liaaen-Jensen, S. Andrewes, A. G. (1985). Analysis of carotenoids and related polyene pigments. In: Gottschalk, G. (ed.) Methods in microbiology. Academic Press, New York, p. 235-283

Lorenzen, C. J. (1967). Determination of chlorophyll and pheopigments: spectrophotometric equations. Limnol. Oceanogr 12: $343-346$

Mann, J E., Myers, J. (1968). On pigments, growth, and photosynthesis of Phaeodactylum tricornutum. J. Phycol. 4: $349-355$

Maske, H., Haardt, H. (1987). Quantitative in vivo absorption spectra of phytoplankton: detrital absorption and comparison with fluorescence excitation spectra. Limnol. Oceanogr 32: 620-634

Melis, A., Brown, J. S. (1980). Stoichiometry of system I and system II reaction centers and of plastoquinone in different photosynthetic membranes. Proc. natn. Acad. Sci. U.S.A. 77. $4712-4716$

Mitchell, B. G., Kiefer, D. A. (1984). Determination of absorption and fluorescence excitation spectra for phytoplankton. In: Holm-Hansen, O., Bolis, L., Giles, R. (eds.) Marine phytoplankton and productivity. Springer-Verlag, Berlin, p. $157-169$

Mitchell, B. G., Kiefer, D. A. (1988). Chlorophyll a specific absorption and fluorescence excitation spectra for lightlimited phytoplankton. Deep Sea Res. 35: 639-663

Morel, A., Bricaud, A. (1981). Theoretical results concerning light absorption in a discrete medium, and application to specific absorption of phytoplankton. Deep Sea Res. 28 1375-1393

Owens, T G. (1986). Light-harvesting function in the diatom Phaedactylum tricornutum. II. Distribution of excitation energy between the photosystems. PI. Physiol. 80:739-746

Owens, T G., Gallagher, J. C., Alberte, R. S. (1987). Photosynthetic light-harvesting function of violaxanthin in $\mathrm{Nan}$ nochloropsisspp. (Eustigmatophyceae). J. Phycol. 23: 79-85

Owens, T G., Wold, E. R. (1986). Light-harvesting function in the diatom Phaeodactylum tricornutum. I. Isolation and characterization of pigment-protein complexes. Pl. Physiol 80: $732-738$

Parsons, I R., Maita, Y., Lalli, C. M. (1984). A manual of chemical and biological methods for seawater analysis. Pergamon Press, Toronto

Platt, T (1986). Primary production of the ocean water column as a function of surface light intensity: algorithms for remote sensing. Deep Sea Res. 33: 149-163

Platt, T., Lewis, M. R., Geider, R. (1984). Thermodynamics of the pelagic ecosystem: elementary closure conditions for biological production in the open ocean. In: Fasham, M. J.R. (ed.) Flows of energy and materials in marine ecosystems. NATO Conference Series IV, Marine Sciences 13. Plenum Press, New York, p. 49-84

Platt, T., Sathyendranath, S., Caverhill, C. M., Lewis, M. R. (1988). Ocean primary production and available light: further algorithms for remote sensing. Deep Sea Res. 35: 855-879

Prézelin, B. B. (1980). Light reactions in photosynthesis. Can. Bull. Fish. Aquat. Sci. 210: 1-43

Prézelin, B. B., Boczar, B. A. (1986). Molecular bases of cell absorption and fluorescence in phytoplankton: potential applications to studies in optical oceanography. In: Round, F. E., Chapman, D. J. (eds.) Progress in phycological research, Vol. 4. Biopress Ltd, Bristol, p. 349-464

Prieur, L., Sathyendranath, S. (1981). An optical classification of coastal and oceanic waters based on the specific spectral absorption of phytoplankton pigments, dissolved organic matter, and other particulate materials. Limnol. Oceanogr. 26: $671-689$

Rhiel, E., Morschel, E., Wehrmeyer, W (1987). Characterization and structural analysis of chlorophyll a/c light harvesting complex and of photosystem I particles isolated from thylakoid membranes of Cryptomonas maculata (Cryptophyceae). Eur. J. Cell Biol. 43: 82-92

Richards, F. A., Thompson, T G. (1952). The estimation and characterisation of plankton populations by pigment analysis. II: A spectrophotometric method for the estimation of plankton pigments. J. mar Res. 11-156-172

Ricker, W. E. (1984). Computation and uses of central trend lines. Can. J. Zool. 62: 1897-1905

Rowan, K. S. (1989). Photosynthetic pigments of algae. Cambridge Unversity Press, Cambridge

Sakshaug, E., Kiefer, D. A., Andresen, K. (1989). A steady state description of growth and light absorption in the 
marine planktonic diatom Skeletonema costatum. Limnol. Oceanogr. 34: 198-20

Sathyendranath, S. (1986). Remote sensing of phytoplankton: a review, with special reference to picoplankton. Can. Bull. Fish. Aquat Sci. 214: 561-583

Sathyendranath, S., Gouveia, A. D., Shetye, S. R., Ravindran, P., Platt, T (1991). Biological control of surface temperature in the Arabian Sea. Nature, Lond. 349: 54-56

Sathyendranath, S., Lazzara, L., Prieur, L. (1987). Variations in the spectral values of specific absorption of phytoplankton. Limnol. Oceanogr. 32: 403-415

Sathyendranath, S., Morel, A. (1983). Light emerging from the sea - Interpretation and uses in remote sensing. In: Cracknell, A. P. (ed.) Remote sensing applications in marine science and technology. D. Reidel Publishing Company, Dordrecht, p. 323-357

Sathyendranath, S., Platt, T (1988). The spectral irradiance at the surface and in the interior of the ocean: a model for application in oceanography and remote sensing. J. geophys. Res. 93(C8): 9270-9280

Sathyendranath, S., Platt, T. (1989). Computation of aquatic primary production: extended formalism to include effect of angular and spectral distribution of light. Limnol. Oceanogr. 34: 188-198

SCOR/UNESCO (1966). Determination of photosynthetic pigments in sea water. Monogr. oceanogr. Methodol. 1: 1-69

This article was submitted to the editor
Shipman, L. L., Cotton, T M., Norris, J. R., Katz, J. J. (1976). An analysis of the visible absorption spectrum of chlorophyll a monomer, dimer, and oligomers in solution. J. Am. chem. Soc. 98: 8222-8230

Smith, R. C., Marra, J., Perry, M. J., Baker, K. S., Swift, E., Buskey, E., Kiefer, D. A. (1989). Estimation of a photon budget for the upper ocean in the Sargasso Sea. Limnol. Oceanogr. 34: 1673-1694

Sokal, R. R., Rohlf, F. J. (1969). Biometry. The principles and practice of statistics in biological research. Freeman \& Co. San Francisco

Stauber, J. L., Jeffrey, S. W. (1988). Photosynthetic pigments in fifty-one species of marine diatoms. J. Phycol. 24: $158-172$

Thormber, J. P., Alberte, R. S. (1977). The organization of chlorophyll in vivo. In: Trebst, A., Avron, M. (eds.) Photosynthesis I: Photosythetic electron transport and photophosphorylation. Springer-Verlag, Berlin, p. 574-582

Toyozawa, Y (1958). Theory of line-shapes of the exciton absorption bands. Progr theor Phys. Kyoto 20: 53-81

Yentsch, C. S. (1962). Measurement of visible light absorption by particulate matter in the ocean. Limnol. Oceanogr. 7 : $207-217$

Yentsch, C. S., Phinney, D. A. (1989). A bridge between ocean optics and microbial ecology. Limnol. Oceanogr 34: 1694-1705

Manuscript first received: September 6, 1990

Revised version accepted: March 6, 1991 